Original Article

\title{
Clinical Profile and Outcome of Children with Congenital Heart Disease in First Year of Life
}

\author{
*Rana RA ${ }^{1}$, Khatoon $S^{2}$, Ahmed $\mathrm{MN}^{3}$, Islam $\mathrm{MR}^{4}$, Kabir $S^{5}$, Das $\mathrm{NL}^{6}$, Nahar $Z^{7}$, Jebunnesa ${ }^{8}$, Jobayer $\mathrm{M}^{9}$
}

\begin{abstract}
Diagnosis of congenital heart disease (CHD) which is a structural abnormality of the heart or intra thoracic great vessels in the earliest possible time is very important. Identifying the various modes of presentation, early referral and appropriate intervention can save lives and reduce risk of complications. The objectives of this study were to determine the clinical profile, complication and immediate outcome of children with congenital heart disease in first year of life. This cross-sectional observational study was conducted from October 2011 to March 2012 among 50 children from zero to one year of age who was diagnosed as CHD by echocardiography admitted in Department of Paediatrics of Shaheed Suhrawardy Medical College, Dhaka and Department of Paediatric Cardiology of National Institute of Cardiovascular Diseases, Dhaka, Bangladesh. Among 50 infants acyanotic CHD was detected in $70 \%$ and cyanotic in $30 \%$ infants. Major structural defects were venticular septal
\end{abstract}

1. *Dr. Rubina Afroz Rana, Assistant Professor (Paediatrics), National Center for Control of Rheumatic Fever \& Heart Diseases (NCCRF \& HD), Sher-e-Bangla Nagar, Dhaka. Email: tithi227@gmail.com, Mobile: 01715042364.

2. Dr. Soofia Khatoon, Ex Professor and Head, Department of Paediatrics, Shaheed Suhrawardi Medical College (ShSMC), Dhaka.

3. Dr. Mir Nesaruddin Ahmed, Associate Professor \& Senior Consultant, National Heart Foundation Hospital \& Research Institute (NHFH\&RI) Mirpur, Dhaka.

4. Dr. Md. Rafiqul Islam, Ex Professor, Department of Paediatrics, ShSMC, Dhaka.

5. Dr. Shahreen Kabir, Registrar, Paediatric Cardiology, NHFH\&RI, Dhaka,

6. Dr. Nanda Lal Das, Junior Consultant (Paediatrics), ShSMC, Dhaka.

7. Dr. Zakia Nahar, Associate Professor (Paediatrics), ShSMC, Dhaka.

8. Dr. Jebunnesa, Consultant Paediatrics, Center for Women and Child Health, Ashulia, Dhaka.

9. Dr. Mohammad Jobayer, Assistant Professor, NCCRF \& HD, Sher-e-Bangla Nagar, Dhaka.

${ }^{*}$ For Correspondence defect $34 \%$, patent ductus arteriosus 30\%, tetralogy of fallot's $14 \%$, transposition of great arteries $12 \%$, atrial septal defect 6\%. Presenting features were cough 82\%, dyspnea 80\%, poor weight gain 70\%, feeding difficulty $68 \%$ and fever $58 \%$. Frequently observed complications were failure to thrive, pulmonary hypertension and heart failure. Among the outcome of CHD 8\% cases closed spontaneously, case fatality rate was $8 \%$ and the rest were advised accordingly for surgery, intervention and medical management among which 14\% had device closure within the study period. High index of suspicion, early diagnosis, close monitoring and timely intervention can reduce complication of CHD.

Keywords: Acyanotic, CHD, cyanotic, echocardiography.

\section{INTRODUCTION}

Congenital heart disease (CHD) is a gross structural abnormality of the heart or intra thoracic great vessels that is actually or potentially of functional significance. ${ }^{1}$ The incidence of CHD is $8-10 / 1000$ live births in different parts of the world. ${ }^{2}$ Nearly one third to half of these $\mathrm{CHD}$ are critical requiring intervention in the first year of life. ${ }^{3} \mathrm{CHD}$ is one of the most common types of anomaly that is responsible for significant morbidity and mortality in children. ${ }^{1}$ Presence of congenital heart disease is suspected on the basis of following findings; a) presence of cardiac murmur, b) presence of cyanosis or feeding difficulty, c) cyanosis associated with feeding difficulty, d) features of congestive heart failure or failure to thrive. ${ }^{1}$ Early recognition of $\mathrm{CHD}$ is important because clinical presentation and deterioration may be sudden and some treatable defects may even cause death before diagnosis. ${ }^{4,5}$

CHD is divided into acyanotic and cyanotic, but there are several conditions like tetralogy of Fallot, Ebstein's anomaly, Eisenmenger Syndrome which may start as acyanotic and become cyanotic with time. ${ }^{6}$

Clinical profile of congenital heart disease varies according to type and severity of the defect. In neonate, the presenting features of CHD are cyanosis (with or without respiratory distress), heart failure (with or without cyanosis) an abnormal clinical sign detected on routine 
examination (e.g. absent femoral pulse or a heart murmur). ${ }^{7}$ In infancy and childhood the usual presenting features are cyanosis, digital clubbing, murmur, syncope, squatting, heart failure, arrhythmia, failure to thrive. ${ }^{8}$ $\mathrm{CHD}$ is responsible for more deaths in the first year of life than any other birth defects. Some CHD heal over time, others will require treatment. ${ }^{9}$ In some cases early diagnosis can avoid irreversible pulmonary vascular disease. ${ }^{5}$ With currently available treatment modalities over $75 \%$ of infants born with critical CHD can survive beyond the first year of life and many can lead near normal lives thereafter. Majority of the children born in developing countries and afflicted with CHD do not get the necessary care, leading to high mortality and morbidity. ${ }^{10}$

Diagnosis of CHD at the earliest possible time is very important because early referral and appropriate intervention can save lives and reduce complications.

The objectives of the study was to determine the clinical profile, complications and immediate outcome of children with congenital heart disease in their first year of life who were admitted at hospital during the study period.

\section{MATERIALS AND METHOD}

This cross-sectional observational study was carried out from October 2011 to March 2012 in the Department of Paediatrics of Shaheed Suhrawardy Medical College (ShSMC), Dhaka, Bangladesh. The study enrolled 50 children of day zero to one year of age admitted in the Department of Paediatrics of ShSMC and the Department of Paediatric Cardiology of National Institute of Cardiovascular Diseases (NICVD), Sher-E-Bangla Nagar, Dhaka.

The inclusion criterion was CHD among admitted children from day zero to 1 year of age diagnosed by echocardiography and clinical evaluation.

Fifty infants with congenital heart disease were purposively selected for the study following inclusion exclusion criteria. After enrolment detailed history, presenting clinical features, age at first diagnosis, complication and immediate outcome of the cases were recorded to evaluate their clinical presentation. All the relevant data related were noted in a preformed datasheet by pre-tested semi structured questionnaire. Data were analyzed using Microsoft excel program and were presented as tables and figures.

\section{RESULTS}

Table I Shows this study was done over 50 children of CHD. Among them $62 \%$ cases were diagnosed within 6 months of age and $38 \%$ cases were between 7 to 12 months. Male patients were predominant (54\%) and male female ratio was 1.17:1.

Table I: Distribution of CHD cases by age and sex $(n=50)$.

\begin{tabular}{|l|c|c|c|}
\hline Age group & Male n(\%) & Female n(\%) & Total n(\%) \\
\hline 0-6 months & $16(51.6 \%)$ & $15(48.4 \%)$ & $31(62.00 \%)$ \\
\hline $7-12$ months & $11(57.9 \%)$ & $8(42.1 \%)$ & $19(38.00 \%)$ \\
\hline Total & $27(54 \%)$ & $23(46 \%)$ & $50(100 \%)$ \\
\hline
\end{tabular}

Table II Shows among 50 cases 35 (70\%) were acyanotic heart lesions and $15(30 \%)$ were cyanotic heart lesions. Among all structural defects VSD was predominant and present in $17(34 \%), \mathrm{PDA}$ in $15(30 \%)$ cases, TOF in 7 $(14 \%)$ and TGA in $6(12 \%)$ cases.

\section{Table II Distribution of cases by structural defects of CHD (n=50).}

\begin{tabular}{|c|c|}
\hline Structural Defect & Number (\%) \\
\hline Acyanotic & $35(70)$ \\
\hline VSD & $17(34)$ \\
\hline PDA & $15(30)$ \\
\hline ASD & $3(6)$ \\
\hline Cyanotic & $15(30)$ \\
\hline TOF & $7(14)$ \\
\hline TGA & $6(12)$ \\
\hline TA with ASD & $1(2)$ \\
\hline PS with VSD & $1(2)$ \\
\hline
\end{tabular}

Table III Shows complaints of children with CHD showed cough in most cases $(82 \%)$, dyspnoea in $80 \%$, poor weight gain in $70 \%$, feeding difficulty in $68 \%$ and fever in $58 \%$ cases.

Table III: Distribution of cases with CHD by presenting complaints on admission.

\begin{tabular}{|l|c|}
\hline Complaints & No (\%) \\
\hline Cough & $41(82)$ \\
\hline Dyspnoea & $40(80)$ \\
\hline Poor weight gain & $35(70)$ \\
\hline Feeding difficulty & $34(68$ \\
\hline Fever & $29(58)$ \\
\hline Bluish coloration of lips,fingers & $15(30)$ \\
\hline
\end{tabular}


Table IV Shows murmur was the most common (90\%) presenting sign among children with $\mathrm{CHD}$, followed by tachycardia (82\%); cyanosis was reported in $30 \%$, tender hepatomegaly in $28 \%$, oedema in $12 \%$ and clubbing was found in $4 \%$ cases.

Table IV: Distribution of cases with CHD by presenting signs.

\begin{tabular}{|l|c|}
\hline Signs & Number of child $\mathbf{n}$ (\%) \\
\hline Murmur & $45(90)$ \\
\hline Tachycardia & $41(82)$ \\
\hline Cyanosis & $15(30)$ \\
\hline Hepatomegaly & $14(28)$ \\
\hline Oedema & $6(12)$ \\
\hline Clubbing & $2(4)$ \\
\hline
\end{tabular}

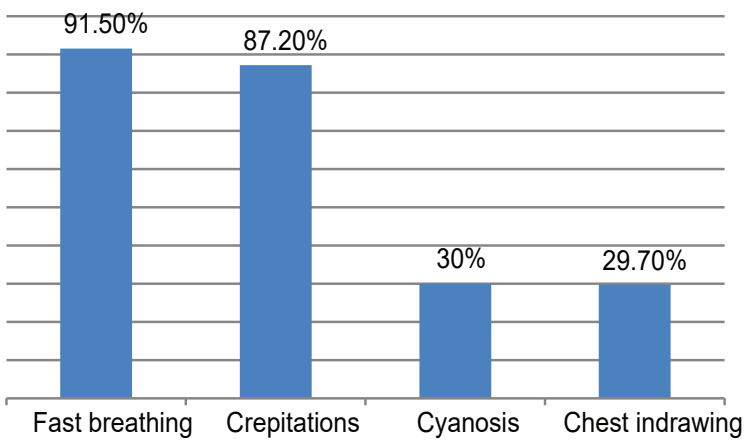

Figure 1: Distribution of respiratory features among cases with $C H D$.

Fig 1: Respiratory features were common, 47(94\%) cases presented with various features of respiratory difficulties like fast breathing in $91.5 \%$, crepitations in $87.2 \%$, cyanosis in 30\% cases, chest indrawing in $29.7 \%$ cases

Table V Shows among both age group 60\% cases had history of more than two episodes of respiratory symptoms.

Table V: Distribution of cases with CHD of different age group by number of attack of respiratory problems $(\mathbf{n}=50)$

\begin{tabular}{|l|c|c|c|c|}
\hline Age group & $\begin{array}{c}\text { Total } \\
\text { Cases }\end{array}$ & $\begin{array}{c}\text { No } \\
\text { episode }\end{array}$ & $\begin{array}{c}\mathbf{\leq 2} \\
\text { episode }\end{array}$ & $\begin{array}{c}>\mathbf{2} \\
\text { episode }\end{array}$ \\
\hline 0- 6 months & 31 & 3 & 11 & 17 \\
\hline 7 - 12 months & 19 & 0 & 6 & 13 \\
\hline Total n (\%) & $\mathbf{5 0 ( 1 0 0 )}$ & $\mathbf{3 ( 6 )}$ & $\mathbf{1 7}(\mathbf{3 4})$ & $\mathbf{3 0 ( 6 0 )}$ \\
\hline
\end{tabular}

Table VI Shows among various complications with CHD, failure to thrive was detected in $76 \%$, heart failure in $28 \%$ and pulmonary hypertension was detected by echocardiography in $34 \%$ cases.

Table VI : Distribution of cases with CHD by complication.

\begin{tabular}{|l|c|}
\hline Complication & No (\%) \\
\hline Failure to thrive & $38(76)$ \\
\hline Pulmonary hypertension & $17(34)$ \\
\hline Heart failure & $14(28)$ \\
\hline
\end{tabular}

Table-IV shows spontaneous closure of CHD was detected in $8 \%$ cases, $14 \%$ underwent device closure and $8 \%$ cases died of which two cases were TGA, one was TOF and the other one was VSD with severe PS with renal mass.

Table-VII: Outcome of CHD in children ( $n=50)$.

\begin{tabular}{|l|c|c|c|c|}
\hline & $\begin{array}{c}\text { Advice for } \\
\text { surgery \&or } \\
\text { conservative } \\
\text { treatment }\end{array}$ & $\begin{array}{c}\text { Closed } \\
\text { Spontaneous } \\
\mathbf{n}(\%)\end{array}$ & $\begin{array}{c}\text { Device } \\
\mathbf{n}(\%)\end{array}$ & $\begin{array}{c}\text { Death } \\
\mathbf{n}(\%)\end{array}$ \\
\hline VSD (17) & $14(28)$ & $3(6)$ & $0(0)$ & $0(0)$ \\
\hline PDA (15) & $7(14)$ & $1(2)$ & $7(14)$ & $0(0)$ \\
\hline TOF (7) & $6(12)$ & $0(0)$ & $0(0)$ & $1(2)$ \\
\hline TGA (6) & $4(8)$ & $0(0)$ & $0(0)$ & $2(4)$ \\
\hline ASD (3) & $3(6)$ & $0(0)$ & $0(0)$ & $0(0)$ \\
\hline TA with ASD (1) & $1(2)$ & $0(0)$ & $0(0)$ & $0(0)$ \\
\hline PS with VSD (1) & $0(0)$ & $0(0)$ & $0(0)$ & $1(2)$ \\
\hline Total n (\%) & $\mathbf{3 5 ( 7 0 )}$ & $\mathbf{4 ( 8 )}$ & $\mathbf{7 ( 1 4 )}$ & $\mathbf{4 ( 8 )}$ \\
\hline
\end{tabular}

\section{DISCUSSION}

Diagnosis of Congenital heart disease at the earliest possible time and identifying the mode of presentation, complications and outcome is very important as early recognition referral and appropriate intervention could save the lives and reduce the risk of further complications.

In this study male patients were predominant (54\%) and male female ratio was 1.17:1. Male sex preponderance in children with CHD was also found by Rahman et al. ${ }^{6}$ Male female ratio of this study was very much consistent with another study in Bangladesh where it was reported as $1.3: 1 .^{11}$ 
This study found that $70 \%$ of CHD cases were acyanotic and $30 \%$ cases were cyanotic heart disease. VSD was the most common structural defects (34\%) with PDA as the second common (30\%), TOF was found in $14 \%$ cases, TGA in $12 \%$ cases and ASD in $6 \%$ cases. It correlates with the findings of Hussain et, al where acyanotic heart disease were found in three-forth cases among which VSD was the commonest acyanotic and TOF was the commonest cyanotic heart disease. ${ }^{12}$ Hoque et al found VSD as the commonest CHD but Begum et al found ASD as the commonest CHD. ${ }^{13,14}$ Structural defect of CHD varies depending upon age group; simple and potentially correctable heart defects like VSD, PDA and ASD are common at all ages. ${ }^{10}$

In the present study $62 \%$ of the cases presented within first 6 months of age and 38\% were first diagnosed between 7 to 12 months. Many CHD may not be diagnosed during neonatal period or at the time of birth. About 30\% CHD may die without a diagnosis, again in case of postnatal CHD who were discharged without a diagnosis, 35\% became unwell or died by 6 weeks of age. ${ }^{4,5}$

The present study is almost consistent with the other study on presenting complaints of children with CHD. ${ }^{11}$ As a presenting complaints cough was found in $82 \%$ cases, dyspnoea in $80 \%$, poor weight gain in $70 \%$, feeding difficulty in $68 \%$, fever in $58 \%$ cases. Sharmin et al found dyspnoea in $60 \%$, cough in $43.5 \%$, poor weight gain in $41.7 \%$, feeding problem in $26 \%$ cases. ${ }^{11}$

Cardiovascular examination revealed murmur in $90 \%$ and $10 \%$ of the children had no murmur but was diagnosed as CHD by clinical evaluation and echocardiogram. In contrast to the findings of this study much higher rate of absence of murmur $(31.82 \%)$ in child with $\mathrm{CHD}$ was reported by Hoque et al and Anisworth et al $(55.36 \%)^{13,15}$ where the age group was limited to neonates only. Other common presenting signs among $\mathrm{CHD}$ cases were tachycardia in $82 \%$ children, cyanosis in $30 \%$, tender hepatomegaly in $28 \%$ and oedema in $12 \%$, which is also similar to sharmin et al showing cyanosis in $20 \%$, and tachycardia in $37.4 \%$ and oedema in $10.4 \%$ cases. ${ }^{11}$

Out of 50 cases 47 cases presented with different respiratory features like fast breathing $91.5 \%$, crepitation on auscultation in $87.2 \%$ and chest indrawing in $29.7 \%$ children. History of repeated respiratory tract infection was detected by Sharmin et $\mathrm{al}^{11}$ in 34\% cases and in this study in $60 \%$ cases which is higher than the previous study. Age group of children was different in two studies and rate is higher among infants below one year of age. Children with history of repeated respiratory tract infection should be sought out and screened for the possibility of CHD.

In this study complication due to $\mathrm{CHD}$ detected were failure to thrive in $76 \%$ cases, heart failure in $28 \%$ and various degree of pulmonary hypertension detected by echocardiography in $34 \%$ cases. Shah et al, stated that considering the age at presentation maximum number of children presented during infancy and failure to thrive was seen in $86.9 \%$ cases and heart failure in $46 \%$ cases. ${ }^{16}$

Six children had associated anomaly like Down syndrome, clubfoot, cleft lip/palate and hypothyroidism. All children with Down syndrome should be screened for CHD after birth. Babies with Down's syndrome were referred for early assessment and echocardiography, yet 34\% remained undiagnosed by 6 weeks of age and $24 \%$ by 12 weeks. ${ }^{5}$

In the current study VSD were detected in 34\% cases with various size. Among them large VSDs (17.65\%) were referred for surgical closure, moderate and small sized VSD were reported in $47.06 \%$ cases and $17.65 \%$ cases were spontaneously closed during study period. VSDs can be closed spontaneously even up to 4 year of age. ${ }^{17}$ Among the 15 cases of PDA $1(6.67 \%)$ case with small PDA was closed spontaneously, 7 (46.6\%) cases had device closure and the rest $7(46.6 \%)$ was on conservative management and advised for closure by one year of age. Fatema et al, found spontaneous closure in $29.16 \% \mathrm{VSD}$ and in $33.3 \%$ PDA cases by first year of life. ${ }^{18}$

Among the outcome of CHD in children, spontaneous closure was detected by echocardiography in $8 \%$ cases and another $8 \%$ children died during the study period. Rest of the children was advised accordingly for surgery, intervention and medical management; among which 14\% had device closure within the study period. Outcome of $70 \%$ cases could not be followed due to constrain of study period. Intervention was not possible in some of the children due to associated complications like failure to thrive, pulmonary hypertension and heart failure. Some patient left the hospital due to financial problem.

\section{CONCLUSIONS}

The modes of presentation of CHD are variable according to age, therefore high index of suspicion, early diagnosis, close monitoring and timely intervention is required for better outcome of children below one year of age. Detection and management of CHD below one year of age can prevent many complications and provide better prognosis of the disease. 


\section{ETHICAL ISSUE}

This study was done with prior permission of the Directors of Shaheed Suhrawardy Medical College Hospital and National Institute of Cardiovascular Diseases. Informed written consent was taken from parents of the children. Anonymity of the participants and confidentially of information was maintained strictly.

\section{CONFLICT OF INTEREST}

We do not have any potential conflicts of interest.

\section{REFERRENCES}

1. Mithcell SC, korones SB, Berendes HW. Congenital heart disease in 56109 births. Incidence and natural history. Circulation. 1971; 43: 323-32.

2. Fyler DC, Buckley LP, hellenbrand WE, Cohn HE. Report at the New England Regional Infant Care Programme. Pediatrics. 1980; 65: 375-461.

3. Hoffman JI and Kalpan S. The incidence of congenital heart disease. J Am Coll Cardiol. 2002; 39: 1890-900.

4. Abu-Harb M, Hey E, Wren C. Death in infancy from unrecognized congenital heart disease. Arch Dis Child. 1994; 71: 3-7.

5. Wren C, Richmond S, Donaldson L. Presentation of congenital heart disease in infancy: implications for routine examination. Arch Dis Child Fetal Neonatal Ed. 1999; 80: 49-53.

6. Rahman S, Ahmed MN, Rahmatullah KHI, Alam MS. The incidence of congenital heart diseases diagnosed by non-invasive technique -ten years study in Bangladesh. Dhaka Shishu Hospital Journal. 1992; 8: 5-15.

7. Kitchner DJ. Cardiovascular disease. In: MMclntosh N Helms PJ, Smyth RL, Forfer \& Arneil's Textbook of Paediatrics, 6th ed. Edinburgh: Churchil Livingstone, 2003; 815-88.

8. Bloomfield P, Bradbury A, Grubb NR, Newby DE. Cardiovascular Disease. In: Bonn NA, Colledge NR, Walker BR, 20th ed. Davidson's principle and practice of Medicine. Edinburgh: Churchil Livingstone, 2006; 519-646.

9. Khairy P, Ionescu-Ittu R, Mackie AS, Abrahamowicz M, Pilote L, Marelli AJ. Changing Mortality in Congenital Heart Disease. J Am Coll Cardiol. 2010; 56: 1149-57.

10. Anita S. Congenital heart disease in India: A status report. Indian J Pediatr. 2005; 72: 595-8.

11. Sharmin LS, Haque MA, Bari MI, Ali MA. Pattern and clinical profile of congenital heart disease in a teaching Hospital. Journal of Teachers Association. 2008; 21: 58-62.

12. Hussain M, Tahura S, Sayeed MA, Rahman MM, Rahman MM, Kar SK. Past and present pattern of congenital heart disease at Dhaka Shishu Hospital: A situation analysis. Bangladesh J Child Health. 2010; 34: 51-5.

13. Hoque MM, Begum JA, Jahan R, Chowdhury MA, Hussain M. Importance of cardiac murmur in diagnosing congenital heart disease in neonatal period. Bangladesh J Child Health. 2008; 32: 17-20.

14. Begum NNF, Ahmed QS. Pattern of heart disease among neonates and their outcome: one year experience in non-invasive cardiac laboratory of Combined Military Hospital, Dhaka. Bangladesh J Child Health. 2001; 25: 48-52.

15. Anisworth SB, Wyllie JP, Wren C. Prevalence and clinical significance of cardiac murmurs in neonates. Arch Dis Child. 1999; 80: 43-5.

16. Shah G, Singh MK, Pandey TR, Kalakheti BK, Bhandari GP. Incidence of congenital heart disease in tertiary care hospital. Kathmandu University Medical Journal. 2008; 6(21): 33-36

17. Bernstein D. Congenital heart disease. In: Behrman RE, Kleigman RM, Jenson HB, Stanton BF. Nelson textbook of pediatrics, vol-2, 18th ed. Philadelphia: Saunders, 2007; 1878-942.

18. Fatema NN, Chowdhury RB, Chowdhury L. Incidence of congenital heart disease among hospital live birth in a tertiary hospital of Bangladesh. Cardiovascular Journal. 2008; 1: 14-20. 